\title{
Exploring healthcare professionals' views and approaches regarding COVID-19 vaccines
}

\author{
(D) Reyhan Öztürk \\ Polatlı Duatepe State Hospital, Department of Infectious Diseases and Clinical Microbiology, Ankara, Turkey
}

Cite this article as: Öztürk R. Exploring healthcare professionals' views and approaches regarding COVID-19 vaccines. J Health Sci Med 2021; 4(5): 692-697.

\begin{abstract}
Aim: While going through tough times in the fight against the pandemic, healthcare professionals' approaches to vaccination may light a society's way. In our study, we aimed to investigate healthcare professionals' views on COVID-19 vaccines.

Material and Method: We carried out the study with a total of 500 voluntary healthcare professionals between January - April 2021. We administered a survey consisting of 15 multiple choice questions to the participants and put their responses into statistical analyses.

Results: There were a total of 500 participants, among whom 168 were males (33.6\%). The mean age of the participants was 39.68 years (21-62). While the number of physicians was 48 (9.6\%), there were $158(31.6 \%)$ nurses and midwives and 294 $(58.8 \%)$ other healthcare workers. Most of the participants (84.4\%) thought COVID-19 to be a fatal infection. Again, the majority of participants believed in the necessity of vaccines (87\%) and, especially, COVID-19 vaccines (73.2\%). Besides, the rate of those vaccinated against COVID-19 was $82 \%$. Interestingly, only about half of the participants (54\%) believed in the protective effect of the vaccine. The participants pointed out ineffectiveness (34\%) and side effects (28\%) of vaccines as the frequent reasons for non-vaccination. Among those holding positive attitudes towards vaccines, $16.7 \%$ had not been vaccinated yet. A substantial rate of the participants (67.4\%) recommended their acquaintances to get vaccinated against COVID-19, but $6.8 \%$ did not. Sixty-three percent of the participants would trust the locally developed vaccines more. Finally, $67 \%$ of the participants thought that vaccines would play a significant role in ending the pandemic.

Conclusion: In our study, we discovered that the vast majority of healthcare professionals were vaccinated against COVID-19 and adopted a positive approach towards vaccination. Overall, relevant education and informative programs may help increase the number of individuals adopting entirely positive attitudes towards COVID-19 vaccines.
\end{abstract}

Keywords: COVID-19 vaccines, healthcare professionals, survey, approach towards vaccines.

\section{INTRODUCTION}

COVID-19 is an infectious disease caused by SARSCoV-2 and affecting the human respiratory system (1-3). It was first diagnosed in patients with severe pneumonia and flu-like symptoms in China (4). Its rapid and sudden spread has endangered health conditions of people and state economies across the world $(5,6)$. Now, science has put forward advances in its treatment; however, an effective vaccine against the disease is still an urgent and vital need $(7,8)$. It is essential not only because the vaccine may prevent the spread of the disease but also for recovering the social and economic affairs by ensuring herd immunity (9-17). On the one hand, scientists have attempted to develop vaccines, anti-vaccine voices, on the other hand, have the opportunity to reach large masses with the help of social media (18). Ultimately, evaluating the attitudes of healthcare professionals, having to fight against both the disease and vaccine opposition, towards vaccines is deemed critical as such attitudes may have an impact on public opinion. In this study, we explored healthcare professionals' views and approaches regarding COVID-19 vaccines adopting an unbiased perspective.

\section{MATERIAL AND METHOD}

We administered a survey consisting of 15 multiple choice questions to 500 healthcare professionals serving in our hospital (Supplementary material-1) and evaluated their responses. The participants were asked to read the questions carefully and mark the most appropriate option. When needed to collect the data face-to-face, 
we administered the surveys to the participants quickly, complying with the mask-hygiene-physical distance rule. In the survey, the participants were told that they could use their names or any nicknames, but we did not request their other personal information and kept their information confidential. We put the collected data into statistical analyses. All statistical analyses were performed using SPSS for Windows 15.0. We used the Chi-square test to assess parametric data (profession, gender), while it was the Mann-Whitney U test for non-parametric data.

Ethical approval was obtained from the Etlik Zübeyde Hanım Gynecology Training and Research Hospital Clinical Researchs Ethics Committee (Date: 05.26.2021, Decision No: 2021/57). All procedures were carried out in accordance with the ethical rules and the principles of the Declaration of Helsinki. Finally, we received informed consent from all participants.

\section{RESULTS}

\section{Overall Findings}

We carried out all procedures in our study following the 1964 Helsinki Declaration and national/institutional ethical standards. Among the participants, 168 were males $(33.6 \%)$. The mean age of the participants was 39.68 years (21-62). While the number of physicians was 48 (9.6\%), there were 158 (31.6\%) nurses and midwives and 294 (58.8\%) other healthcare workers (Figure 1).

\section{Analysis of the Responses}

To the question "Do you think the COVID-19 is a fatal infection?", 84.4\% answered "Yes," and 9.4\% remained undecided. Then, the question "Who do you think COVID-19 may kill?" was responded to as "Everyone" (82\%), "Only those with chronic diseases" (7\%), and "Only immunocompromised individuals" (4.6\%), respectively.
While 54\% answered "Yes" to the question "Do you think that COVID-19 vaccines provide full protection against the disease?", and 25\% remained neutral. Statistically, we could not reach significant differences between these responses by gender $(\mathrm{p}=0.068)$ and profession $(\mathrm{p}=0.103)$.

While $73.2 \%$ of the participants thought COVID-19 vaccines to be necessary, $17.5 \%$ had no idea about the topic. Among those holding positive attitudes towards vaccination, $83.3 \%$ were vaccinated, but $16.7 \%$ were not. We could not find any significant differences between these responses by gender $(\mathrm{p}=0.441)$ and profession $(\mathrm{p}=0.434)$.

To the question "Do you think vaccines are overall necessary?", $87.0 \%$ answered "Yes." The rate of those who answered "Yes" to the question "Do you think COVID-19 vaccines are necessary?" was $73.2 \%$. Interestingly, $18.2 \%$ of those believing in the necessity of vaccines did not think COVID-19 vaccines were needed. No significant difference was found between these responses by gender $(\mathrm{p}=0.726)$ and profession $(\mathrm{p}=0.434)$ (Figure 2).

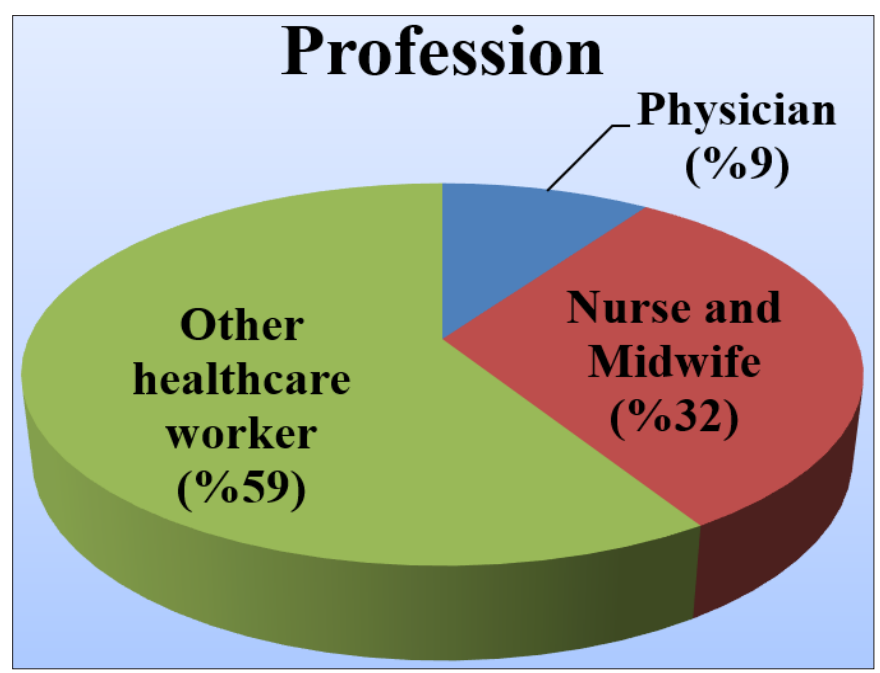

Figure 1. Distribution of the participants by profession

\section{Supplementary material 1 . Survey questions}

\section{Survey Questions}

1. Do you think COVID-19 is a fatal infection?

2. Who do you think may COVID-19 kill?

3. Do you think that COVID-19 vaccines provide full protection against the disease?

4. Do you think COVID-19 vaccines are necessary?

5. Do you think vaccines are overall necessary?

6. Have any of COVID-19 vaccines shown any side effects on your relatives/acquaintances?

7. How do COVID-19 vaccines work?

8. Where have you got information about COVID-19 vaccines?

9. Do you recommend COVID-19 vaccines to your acquaintances?

10. What do you think is the most common side effect of COVID-19 vaccines?

11. Have you got vaccinated?

12. If not, what is your reason for not getting vaccinated?

13. Have you ever had any vaccine (such as influenza, pneumococcus) other than your childhood vaccines?

14. If a locally developed vaccine was introduced in our country, would you trust that vaccine?

15. Do you think vaccines will help end the pandemic? 


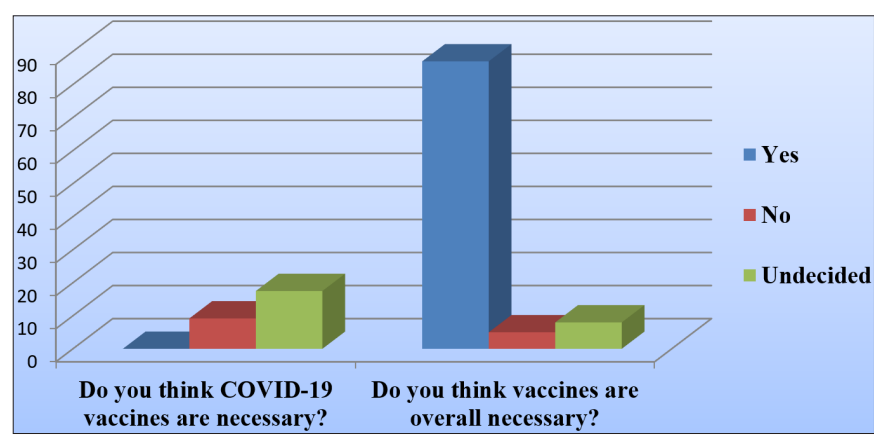

Figure 2. The participants' attitudes towards vaccines

About a quarter of the participants (14.6\%) reported that their relatives developed some symptoms following vaccination. When asked "Where did you get the information about COVID-19 vaccines?", the participants pointed out media $(28.8 \%)$ and their physicians (25\%). The physicians answered this question mostly as "from scientific journals and publications," which differed significantly between physicians and other healthcare professionals in the study ( $\mathrm{p}=0.003)$.

We also concluded that $67.4 \%$ of the participants recommended COVID-19 vaccines to their acquaintances. The male participants were found to be significantly more negative in this issue than their female counterparts $(\mathrm{p}=0.024)$. However, almost all participating physicians recommended vaccines to others (91.6\%), and a significant difference was found between the physicians and others by vaccine recommendation $(\mathrm{p}=0.003)$. While $53.8 \%$ answered the question "What do you think is the most common side effect of the COVID-19 vaccine?" as "allergic reactions," $20.8 \%$ pointed out "influenza causing mortality." Other responses were shown in table (Table 1).

Table 1. Answers of the question "What do you think is the most common side effect of the COVID-19 vaccine"

\begin{tabular}{|lc|}
\hline Answers & Percentage (\%) \\
\hline Allergic reactions & 53.8 \\
Influenza causing mortality & 20.8 \\
Paralysis and neurological disorders & 3.4 \\
Heart failure & 2.6 \\
Infertility & 1.4 \\
\hline
\end{tabular}

The vast majority of the participants had already been vaccinated $(82.0 \%)$. The vaccination rate was $91.0 \%$ among the physicians, $71.0 \%$ among nurses and midwives, and $74.0 \%$ among other healthcare workers. This rate was significantly higher in the physicians than in the other groups $(p<0.001)$. When asked about the reason(s) for not getting vaccinated, the most common response was related to perceived ineffectiveness of vaccines (34\%). This response was followed by thoughts that vaccines have many side effects (28\%) and that people can protect themselves against COVID-19 only by using a mask and complying with the physical distance rule (25\%) (Table 2).

\begin{tabular}{|lc|}
\hline Table 2. Reasons for not getting vaccinated & Percentage \% \\
\hline Reason & 34 \\
\hline Vaccines are ineffective & 28 \\
Vaccines have many side effects & 25 \\
$\begin{array}{l}\text { People can protect themselves by complying } \\
\text { only with the mask-hygiene-distance rule }\end{array}$ & 3 \\
$\begin{array}{l}\text { I have experienced severe side effects of } \\
\text { previous vaccines }\end{array}$ & 10 \\
\hline I am allergic to vaccines & \\
\hline
\end{tabular}

Among the participants, $63 \%$ stated that they would trust locally developed vaccines more, but $30.3 \%$ would still remain neutral. While $67 \%$ of the participants thought that vaccines would help end the pandemic, $10 \%$ did not.

\section{DISCUSSION}

The denying approach to vaccines, which are the most critical weapons in combating infectious diseases, has been on the agenda since the very first day vaccines were introduced $(18,19)$. Defined as behavior patterns ranging from being against a specific vaccine to rejecting all vaccines, vaccine opposition threatens community health (19). The most damaging vaccine deception of the last century has been the article published in "The Lancet," which reports a so-called association between the measles vaccine and autism $(19,20)$. Although it was realized that the study data were falsified, which led it to be removed from publication, it caused a decrease in the reliability of the measles vaccine and an increase in measles in the population (20). Besides, the unstoppable rise in sharing health-related issues on social media causes information pollution and helps the rapid spread of misinformation, which can provoke anti-vaccination $(19,20)$.

On the other hand, it is known that informing families by healthcare professionals contributes to vaccination rates, which implies that healthcare professionals have a critical role in families' decisions on the vaccination of their children $(21,22)$. In a study by the European Center for Disease Prevention and Control group in 2015 to identify vaccine hesitancy among healthcare workers and their patients, the most reliable source of information on vaccines was found to be healthcare professionals (23).

In our study, $6.2 \%$ of the participants thought the COVID-19 infection was not fatal, while 9.4\% remained neutral. In a study by Ergün et al. (24), the participating healthcare professionals were asked how adequately they considered their COVID-19-oriented knowledge. Accordingly, they concluded that the majority of the participants $(80 \%)$ found their knowledge adequate. The idea that the COVID-19 infection is not fatal among healthcare professionals, despite working in hospitals and seeing deaths from COVID-19, may be because they have insufficient knowledge on the subject. 
In our study, 54\% thought COVID-19 vaccines would provide robust protection against the disease, while $21 \%$ thought vice versa, and $25 \%$ remained undecided. However, those who were unsure about the protection of vaccines also got vaccinated (82\%). Interestingly, we determined that $16.7 \%$ of those thinking vaccines were needed did not get vaccinated, which may be due to vaccine hesitancy of people.

In the study of Arslanca et al. (25), 66.93\% of the healthcare professionals considered getting vaccinated against COVID-19, and $10.36 \%$ remained undecided. Brunon et al. (26) determined a positive approach towards COVID-19 vaccines at a rate of $75 \%$ among healthcare professionals. The rate of positive approach towards the seasonal flu vaccine among the participants was reported to be $57.3 \%$ in the previous season. In our study, we determined that $18 \%$ of the participants were not vaccinated, and this rate was higher among nonphysician healthcare workers.

Dror et al. (27) found that physicians had significantly more positive attitudes towards COVID-19 vaccines than nurses ( $73 \%$ vs. $61 \%$, respectively) . Vaccination may be counted among the most important factors to be able to end such a global crisis, so it seems healthcare professionals need to engage in a continuous update of their knowledge, which may contribute to the rise of vaccination rates. In a study by Ünal et al. (28), family physicians were recruited for one-day training by infectious diseases and internal medicine specialists. The cross-sectional data obtained six months after the program revealed that the vaccination rate among the participants increased from $33.9 \%$ to $45.5 \%$.

The same study by Dror et al. (27) also revealed that the male participants accepted vaccination more, which may be because men are more prone to COVID-19 or some diseases considered risk factors for COVID-19, such as cardiovascular diseases, cancer, or chronic respiratory diseases, appear more in men. Lazarus et al. (29) carried out a study with 13,426 participants from 19 countries and asked the participants, "Do you think COVID-19 vaccines are helpful?" Overall, $46.8 \%$ strongly agreed, $24.7 \%$ partially agreed, $14.2 \%$ had no idea, and $8.1 \%$ did not agree with the question. In our study, about one-third of the participants (34\%) assumed COVID-19 vaccines were ineffective, which was the most important reason for non-vaccination. Other reasons were "vaccines have many side effects" (28\%) and "mask-hygiene-distance rule is the best to be protected from the disease" (25\%).

In the study by Dror et al. (27), both healthcare professionals and other people commonly adopted concerns about the quality and side effects of vaccines because they were developed rapidly. Biswas et al. (30) found that the mostcommon reasons uttered by healthcare professionals who did not want to get vaccinated were related to hesitations about the effectiveness, safety, and side effects of vaccines. The researchers concluded insufficient knowledge about vaccines and perception of COVID-19 not to be a severe disease as other reasons for non-vaccination. In the study of Arslanca et al. (25), all participants thought COVID-19 to be a fatal infection. Although the reasons for not getting vaccinated showed a similarity between our study and the literature, the rate of considering COVID-19 to be a fatal infection was a bit different in our study (84.4\%).

Lucia et al. (31) performed a study with 168 medical students in the United States and found that $76.7 \%$ of the participants had concerns about the effect of COVID-19 vaccines. In addition, this rate was found to be $83.8 \%$ among those who were reluctant to participate in a vaccine trial. In our country, few studies explored the attitudes of healthcare professionals and people towards the flu vaccine. In their study with 371 participants, Kul et al. (32) found that the participants showed the reasons for not having the flu vaccine as disbelief in the necessity of vaccines $(26.0 \%)$, preferring other prevention methods (22.1\%), fear of its side effects (18.3\%), and inadequate trial of the vaccine (11.4\%). Sar1 et al. (33) documented different rates of these reasons: disbelief in the necessity of vaccines (64.5\%), preferring other prevention methods (40.9\%), and fear of its side effects (39.1\%).

Almost all of the participants (98\%) in the study by Lucia et al. (31) stated that COVID-19 vaccines were vital in preventing the spread of the disease, but only $53 \%$ would agree to participate in a vaccine trial. In addition, this rate was found to be higher among clinical students than preclinical students. In the same study, the rate of those thinking that vaccination against COVID-19 should be mandatory for the public was $67.9 \%$, while $85.9 \%$ thought it should be mandatory for healthcare workers (31). In our study, most of the participants (87\%) thought vaccines were overall necessary, but this rate slightly dropped when it came to COVID-19 vaccines (73.2\%). Among those who believed that vaccines were overall needed, 18.2\% considered COVID-19 vaccines were unnecessary. About a quarter of the participants (13\%) found vaccines unnecessary, which indicates that antivaccine views exist even among healthcare professionals. Relevant education programs, positive campaigns on social media, and vaccination-friendly policies may contribute to the elimination of vaccine opposition.

Dror et al. (27) concluded the participating healthcare professionals had much lower acceptance rates of COVID-19 vaccines than the flu vaccine. Also, it was determined that those who had a seasonal flu vaccine adopted more positive approaches towards COVID-19 
vaccines. In the research by Lazarus, 31.9\% strongly agreed, 9.8\% strongly disagreed, and $20.6 \%$ were undecided with the question, "If a COVID-19 vaccine was announced to be safe and effective and recommended by the government, would you accept it?" (29). In our study, $63 \%$ of the participants would trust locally-developed vaccines more, while $30.3 \%$ remained neutral. Finally, while $67 \%$ of the participants thought vaccines would help end the pandemic, $10 \%$ stated that they would not be effective.

\section{CONCLUSION}

During the pandemic, healthcare professionals had to fight the disease, as well as struggling with the increasing vaccine opposition. Therefore, healthcare professionals' views on vaccines may guide public opinion on vaccines. Our results suggested that the majority of the participants had positive approaches to vaccines. Accordingly, relevant education programs on vaccines may help foster such desirable approaches and have intended impacts on vaccination rates.

\section{ETHICAL DECLARATIONS}

Ethics Committee Approval: Ethical approval was obtained from the Etlik Zübeyde Hanım Gynecology Training and Research Hospital Clinical Researchs Ethics Committee (Date: 05.26.2021, Decision No: 2021/57)

Informed Consent: All patients signed the free and informed consent form.

Referee Evaluation Process: Externally peer-reviewed.

Conflict of Interest Statement: The authors have no conflicts of interest to declare.

Financial Disclosure: The authors declared that this study had received no financial support.

Author Contributions: All of the authors declare that they have all participated in the design, execution, and analysis of the paper and approved the final version.

Acknowledgment: A part of this study was presented as an oral presentation at the 9th Turkey Ekmud Scientific Platform on May 22, 2021.

\section{REFERENCES}

1. Taleghani N, Taghipour F. Diagnosis of COVID-19 for controlling the pandemic: A review of the state-of-the-art. Biosens Bioelectron 2021; 174: 112830.

2. Mohamadian M, Chiti H, Shoghli A, Biglari S, Parsamanesh N, Esmaeilzadeh A. COVID-19: Virology, biology and novel laboratory diagnosis. J Gene Med 2021; 23: e3303.

3. Umakanthan S, Sahu P, Ranade AV, et al. Origin, transmission, diagnosis and management of coronavirus disease 2019 (COVID-19). Postgrad Med J 2020; 96: 753-8.

4. Yüce M, Filiztekin E, Özkaya KG. COVID-19 diagnosis - A review of current methods. Biosens Bioelectron 2021; 172: 112752.
5. Habas K, Nganwuchu C, Shahzad F, et al. Resolution of coronavirus disease 2019 (COVID-19). Expert Rev Anti Infect Ther 2020; 18: 1201-11.

6. Islam KU, Iqbal J. An Update on Molecular Diagnostics for COVID-19. Front Cell Infect Microbiol 2020; 10: 560616.

7. Soleimanpour S, Yaghoubi A. COVID-19 vaccine: where are we now and where should we go? Expert Rev Vaccines 2021; 20: 2344.

8. Awadasseid A, Wu Y, Tanaka Y, Zhang W. Current advances in the development of SARS-CoV-2 vaccines. Int J Biol Sci 2021; 17 . 8-19.

9. Sharma NK, Sarode SC, Sarode G, Patil S. Is a COVID-19 vaccine developed by nature already at work? Med Hypotheses 2020; 145: 110335.

10. Sreepadmanabh M, Sahu AK, Chande A. COVID-19: Advances in diagnostic tools, treatment strategies, and vaccine development. J Biosci 2020; 45: 148.

11.Li YD, Chi WY, Su JH, Ferrall L, Hung CF, Wu TC. Coronavirus vaccine development: from SARS and MERS to COVID-19. J Biomed Sci 2020; 27: 104.

12. Silveira MM, Moreira GMSG, Mendonça M. DNA vaccines against COVID-19: Perspectives and challenges. Life Sci 2021; 267: 118919 .

13. Mehrotra DV, Janes HE, Fleming TR, et al. Clinical Endpoints for evaluating efficacy in COVID-19 vaccine trials. Ann Intern Med 2021; 174: 221-8.

14. Marian AJ. Current state of vaccine development and targeted therapies for COVID-19: impact of basic science discoveries. Cardiovasc Pathol 2021; 50: 107278.

15.Liu X, Liu C, Liu G, Luo W, Xia N. COVID-19: Progress in diagnostics, therapy and vaccination. Theranostics 2020; 10: 7821-35

16. Chung JY, Thone MN, Kwon YJ. COVID-19 vaccines: The status and perspectives in delivery points of view. Adv Drug Deliv Rev 2021; 170: 1-25.

17. Halstead SB, Katzelnick L. COVID-19 Vaccines: Should We Fear ADE? J Infect Dis 2020; 222: 1946-50.

18. Omer SB, Salmon DA, Orenstein WA, deHart MP, Halsey N. Vaccine refusal, mandatory immunization, and the risks of vaccine-preventable diseases. N Engl J Med 2009; 360: 1981-8.

19. Kader Ç. Aşı Karşıtlığı: Aşı Kararsızlığı Ve Aşı Reddi. ESTÜDAM Halk Sağlığ

20. Wakefield A, Murch S, Anthony A, et al. İleal-lenfoidnodülerhiperplazi, spesifik olmayan kolit ve çocuklarda yaygın gelişimsel bozukluk. Lancet 1998; 351: 637-41.

21.Puri N, Coomes EA, Haghbayan H, Gunaratne K. Social media and vaccine hesitancy: new updates for the era of COVID-19 and globalized infectious diseases. Hum VaccinImmunother 2020; 16: 2586-93.

22. Argüt N, Yetim A, Gökçay G. Aşı kabulünü etkileyen faktörler. Çocuk Derg 2016; 16: 16-24.

23. Karafillakis E, Dinca I, Apfel F, et al. Vaccine hesitancy among healthcare workers and their patients in Europe: A Qualitative Study. Vaccine 2016; 34: 5013-20.

24. Ergün E, Ergün Ş, Çelebi İ. Acil Sağlık Hizmetleri Personellerinin COVID-19 Hakkında Bilgi, Korunma Düzeyleri Ve Etkileyen Etmenler. JOPEHS 2020; 1: 16-27.

25. Arslanca T, Fidan C, Daggez M, Dursun P. Knowledge, preventive behaviors and risk perception of the COVID-19 pandemic: A cross-sectional study in Turkish health care workers. PLoS One 2021; 16: e0250017.

26. Gagneux-Brunon A, Detoc M, Bruel S, et al. Intention to get vaccinations against COVID-19 in French healthcare workers during the first pandemic wave: a cross-sectional survey. J Hosp Infect $2021 ; 108: 168-73$. 
27. Dror AA, Eisenbach N, Taiber S, et al. Vaccine hesitancy: the next challenge in the fight against COVID-19. Eur J Epidemiol 2020; 35: 775-9.

28. Ünal S , Tanrı̈ver MD, Taș E, Güner İ, Cetin ÖY, Sayar İ. Aile Hekimlerine Eğitim Verilmesi Ve Aşılama Hedeflerinin Belirlenmesinin Pnömokok Așılanma Oranları Üzerine Etkileri. FLORA 2015; 20: 10-15

29. Lazarus JV, Ratzan SC, Palayew A, et al. A global survey of potential acceptance of a COVID-19 vaccine. Nat Med 2021; 27: 225-8.

30. Biswas N, Mustapha T, Khubchandani J, Price JH. The nature and extent of COVID-19 vaccination hesitancy in healthcare workers. J Community Health 2021; 20: 1-8.

31.Lucia VC, Kelekar A, Afonso NM. COVID-19 vaccine hesitancy among medical students. J Public Health (Oxf) 2020: fdaa230.

32.Kul G, Korkmaz N. Sağlık Çalıșanlarının İnfluenza Așılamasına Yaklaşımı. J Contemp Med 2020; 10: 421-4.

33. Sarı T, Temoçin F, Köse H. Sağlık çalışanlarının influenza aşısına yaklaşımları. Türkiye Klinik Derg 2017; 30: 59-63. 